J. Dairy Sci. 103:10961-10961

https://doi.org/10.3168/jds.2020-103-11-10961

๑ 2020 American Dairy Science Association ${ }^{\circledR}$. Published by Elsevier Inc. and Fass Inc. All rights reserved.

\title{
Corrigendum to "A synbiotic combination of Lactobacillus gasseri 505 and Cudrania tricuspidata leaf extract prevents hepatic toxicity induced by colorectal cancer in mice" (J. Dairy Sci. 103:2947-2955)
}

Nam Su Oh, Jae Yeon Joung, Ji Young Lee, Youn Jeong Kim, Younghoon Kim, and Sae Hun Kim

The affiliation for author Sae Hun Kim was shown incorrectly on the title page (page 2947). Dr. Kim is affiliated with the Department of Biotechnology, College of Life Sciences and Biotechnology, Korea University, Seoul, 02841, Korea (affiliation 3).

\section{REFERENCES}

Oh, N. S., J. Y. Joung, J. Y. Lee, Y. J. Kim, Y. Kim, and S. H. Kim. 2020. A synbiotic combination of Lactobacillus gasseri 505 and Cudrania tricuspidata leaf extract prevents hepatic toxicity induced by colorectal cancer in mice. J. Dairy Sci. 103(4):2947-2955. https://doi.org/10 $.3168 /$ jds.2019-17411. 